\title{
Process for coating surfaces with a copolymer made from sulfur and dicyclopentadiene
}

Received 00th January 20xx, Accepted 00th January 20xx DOI: $10.1039 / \times 0 \times x 00000 x$

\author{
Maximilian Mann, ${ }^{a}$ Bowen Zhang, ${ }^{\text {b }}$ Samuel J. Tonkin, ${ }^{\text {a } C h r i s t o p h e r ~ T . ~ G i b s o n, ~}{ }^{c}$ Zhongfan Jia, ${ }^{a}$ Tom \\ Hasell*b and Justin M. Chalker*a
}

\section{Introduction}

The reaction between sulfur and dicyclopentadiene (DCPD) has been investigated for nearly half a century, providing a processible form of sulfur useful in the construction and composites industries..$^{1-5}$ In these applications, the sulfur is primarily unreacted elemental sulfur dissolved or "plasticised" in a solution of low molecular weight polysulfides derived from a relatively low feed ratio of DCPD (typically $25 \%$ or less by mass). $1^{1-5}$ These mixtures can be processed as liquids at elevated temperatures $\left(\sim 130-140^{\circ} \mathrm{C}\right)$ and used as mortar for concrete buildings, ${ }^{2}$ sealants for tailings ponds, ${ }^{2}$ or reinforcement for plastic and glass fibres. ${ }^{3}$ Recently, we revisited copolymerisations of sulfur and DCPD, ${ }^{6}$ establishing how the feed ratio can be used to tune the thermal and mechanical properties of these polymers., 7 In these prior studies, sulfur was fully incorporated into the final, cured polymer, distinguishing these materials from the earlier sulfur plasticisation studies.

Fully crosslinked copolymers made from sulfur and DCPD have useful properties such as high hardness and modulus, and solvent resistance. ${ }^{6,7}$ These properties would be advantageous for coating applications, but the insolubility of these crosslinked polymers makes processing difficult. Here, we present a robust process for overcoming the intractability of the target copolymer.

First, sulfur is reacted with the more reactive norbornene alkene ${ }^{8}$ of DCPD to provide linear, solution processible oligomers (1). The oligomers are shelf stable and can be easily coated onto diverse substrates. Upon curing, in situ S-S metathesis as well as addition to the cyclopentenyl alkene provides the cross-linked polymer coating.

While there have been reports of sulfur-based pre-polymer resins for delayed curing ${ }^{9}$ or chemically induced curing, ${ }^{10}$ this

\footnotetext{
a. Institute for Nanoscale Science and Technology, College of Science and Engineering, Flinders University Bedford Park, South Australia 5042, Australia E-mail: justin.chalker@flinders.edu.au Web:www.chalkerlab.com

b. Department of Chemistry, University of Liverpool, L69 7ZD, United Kingdom E-mail:T.Hasell@liverpool.ac.uk

c. Flinders Microscopy and Microanalysis, College of Science and Engineering, Flinders University, Bedford Park, Adelaide, South Australia, 5042, Australia † Electronic Supplementary Information (ESI) available: full experimental details and characterisation data. See DOI: 10.1039/x0xx00000x
}

concept has not been explored on the simplest sulfur-DCPD system. Additionally, the coating was demonstrated to be resistant to solvent and acid, and useful in the removal of mercury from mixtures of water and hydrocarbons - a new application for this polymer system. The method of synthesis is also safer than other previous protocols which can result in runaway reactions. ${ }^{6,} 11$ Given how the development of inverse vulcanisation, ${ }^{12}$ has renewed the interest in polymers made from sulfur, ${ }^{13-17}$ this is an important finding.

\section{Results and discussion}

First, we aimed to establish a safe and reliable protocol to form a soluble pre-polymer through the reaction of sulfur and DCPD. For safety, it was important to run the reaction at lower temperatures than those typically used in inverse vulcanisation $\left(160\right.$ to $185{ }^{\circ} \mathrm{C}$ ), including the reaction of sulfur and DCPD. ${ }^{6,9}$ At these elevated temperatures, dicyclopentadiene can undergo a retro Diels-Alder reaction, generating cyclopentadiene (S7). In such a situation, the amount of alkenes in the reaction system increases which could result in an uncontrolled increase in the reaction rate of this exothermic reaction. ${ }^{2}$ Cyclopentadiene is also a gas at these temperatures, which could lead to reagent loss and fluctuations in pressure. Indeed, the direct reaction of DCPD and sulfur at these elevated temperatures is known to result in unsafe, runaway reactions. ${ }^{2,} 6,11$ And while accelerators and catalysts can be used to run this reaction at a lower temperature, ${ }^{11}$ these additives remain in the polymer at the end of the synthesis. We therefore investigated the catalyst-free reaction of DCPD in molten sulfur at $140{ }^{\circ} \mathrm{C}$. At this temperature, there is minimal conversion of DCPD to cyclopentadiene ( $3 \%$ based on ${ }^{1} \mathrm{H}$ NMR analysis) (S8). And while ringopening polymerisation of sulfur does not occur at this temperature ${ }^{18}$ (potentially distinguishing this reaction mechanism from those proposed for other inverse vulcanisation reactions), ${ }^{14,15}$, 19 it is known that DCPD and sulfur react at $140{ }^{\circ} \mathrm{C}$, first forming cyclic polysulfides across the norbornene alkene, with oligomerisation upon prolonged heating. ${ }^{3-5}$ Importantly, however, the amount of sulfur in these earlier reports was typically far more than the report here which resulted in substantial free sulfur which ultimately crystallises from the product and causes embrittlement. ${ }^{1-5}$ 
To benchmark the reaction at lower temperature, equal masses of DCPD (>95\% endo) and sulfur ( $3.0 \mathrm{~g}$ each) were placed in a $20 \mathrm{~mL}$ glass vial and incubated, uncapped, in an oven at $140{ }^{\circ} \mathrm{C}$ for up to 24 hours (S10). This feed ratio corresponds to an average of 2 sulfur atoms per alkene, which was expected to provide a greater thermal ${ }^{7}$ and chemical stability 20,21 than materials with longer and more labile polysulfide crosslinks. ${ }^{20,21}$ At least 3 hours were required for the twophase reaction to darken and appear homogenous, even without stirring. Incubating longer than 10 hours resulted in a substantial amount of material that was insoluble in chloroform, which is undesirable for subsequent solvent processing. ${ }^{1} \mathrm{H}$ NMR analysis indicated consumption of the norbornene alkene over 8 hours, and then slower consumption of remaining alkenes over the next $24 \mathrm{~h}$ at $140{ }^{\circ} \mathrm{C}$ (S11). Continued heating after 8 hours resulted in a linear increase in $T_{g}$ with incubation time, consistent with crosslinking (S12). Importantly, this protocol never caused a runaway reaction.

To facilitate mass transfer and potentially increase reaction rate, the reaction was next run at $140{ }^{\circ} \mathrm{C}$ in a hot block with stirring. Running the reaction open to air (even for a mere 2 hours) resulted in a substantial amount of insoluble material. IR analysis of this insoluble fraction revealed unreacted alkenes (S13) and an overall lower fraction of carbon and sulfur by elemental analysis when compared to the soluble fraction (S13). In contrast, running the reaction under nitrogen in a rigorously dry reaction vessel overcame this issue. Control experiments indicated that water can interfere with the reaction and result in insoluble material (S12-S13), so reactions were subsequently run under a nitrogen atmosphere under anhydrous conditions. The preferred protocol for making oligomer 1 was therefore the direct reaction of equal masses of sulfur and DCPD at $140{ }^{\circ} \mathrm{C}$, stirred vigorously for 2 hours under an atmosphere of nitrogen. The resulting material (1) formed a flexible solid on cooling to room temperature (Fig. 1a). Importantly, $\mathbf{1}$ was fully soluble in chloroform, which met the goal of accessing a solution-processible pre-polymer. This product was stable for more than 8 months and no elemental sulfur crystallised over this period.

NMR analysis of 1 indicated partial consumption of DCPD alkenes. Peaks at 3.5-4.0 ppm in the ${ }^{1} \mathrm{H}$ NMR spectra were consistent with signals from CHS groups (Fig. 1c). Signals between 60-75 ppm in the ${ }^{13} \mathrm{C}$ NMR spectra were also consistent with the formation of C-S bonds (Fig. 1d). XRD analysis of 1 indicated that no crystalline sulfur was present (Fig. 1b), as did differential scanning calorimetry (DSC), which did not reveal the melting transition of sulfur. DSC was also used to measure a $T_{g}=3^{\circ} \mathrm{C}$ (S16). Thermogravimetric analysis (TGA) indicated two mass losses, with the first onset at $160{ }^{\circ} \mathrm{C}$ and the second above $250{ }^{\circ} \mathrm{C}$ (Fig. 1f). Laser desorption mass spectrometry (LD-MS) revealed a mixture of species between $\mathrm{m} / \mathrm{z}$ of 600 and 1000 , each separated by 32 mass units, consistent with the proposed oligomeric polysulfide structure (Fig. 1e). Gel permeation chromatography (GPC) indicated a $M_{\mathrm{w}}$ of $1100 \mathrm{~g} \mathrm{~mol}^{-1}$ for 1 (based on comparison to polystyrene standards, S17). The polydispersity of
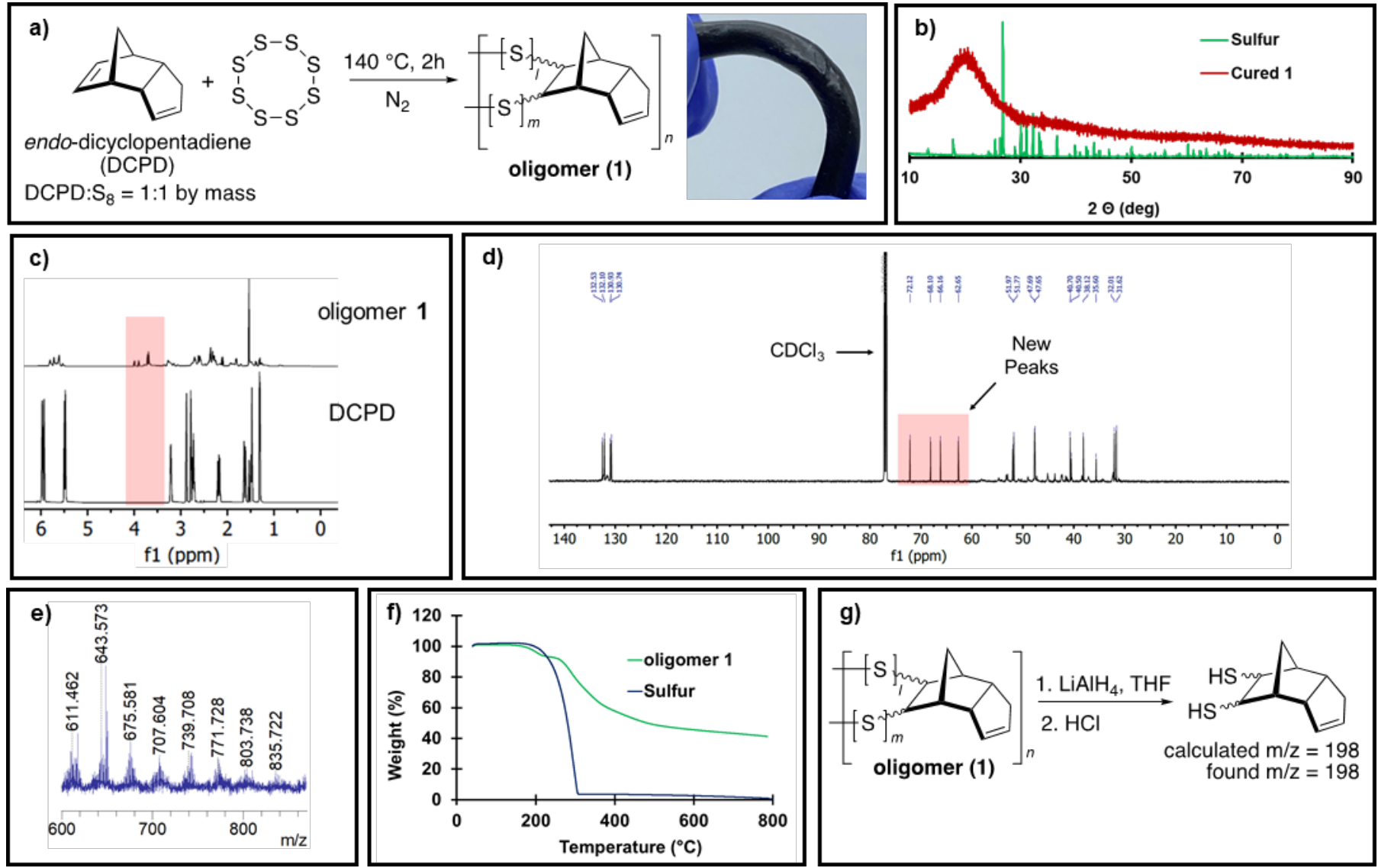

Figure 1. a) Synthesis of oligomer 1 and image showing its flexibility. b) XRD of oligomer 1 indicates no crystalline sulfur present. c) ${ }^{1} \mathrm{H}$ NMR of oligomer 1 and DCPD indicates partial consumption of alkenes between 5.5-6.5 ppm and the formation of C $\mathrm{HS}$ groups between 3.5-4.0 ppm. d) ${ }^{13} \mathrm{C} \mathrm{NMR}$ of DCPD and oligomer 1 showing the formation of new peaks due to C-S bond formation. e) Laser desorption mass spectrometry (LD-MS) showing a distribution of species with a mass range spanning $\sim 600-1000 \mathrm{Da}$. Peak separation of 32 mass units is consistent with a mixture of polysulfides. f) TGA analysis of oligomer 1 revealed two mass losses. The first one starting at around $160^{\circ} \mathrm{C}$. The second mass loss occurs above $250^{\circ} \mathrm{C}$. g) Reduction of 1 provided the expected dithiol as the major product (GC-MS). 
the product also increased over the reaction from $\oslash=1.4$ (60 minutes) to $Ð=1.9$ (120 minutes) (S18). Finally, reduction of 1 with $\mathrm{LiAlH}_{4}$ provided the expected thiol products from reaction of sulfur with the strained norbornene alkenes of DCPD (Fig. 1g), as determined by GC-MS (S19-S25).

With the preparation and characterisation of oligomer 1 complete, thermal curing was investigated next. The hypothesis was that prolonged heating at $140{ }^{\circ} \mathrm{C}$ could induce S-S metathesis reactions as well as reaction of the intermediate thiyl radicals with unreacted alkenes in 1, resulting in a cross-linked material. Indeed, curing oligomer 1 at $140{ }^{\circ} \mathrm{C}$ for 24 hours resulted in continued reaction: the $T_{\mathrm{g}}$ increased to $106{ }^{\circ} \mathrm{C}$, providing a hard and brittle material (Fig. 2b). Solubility studies showed that cured $\mathbf{1}$ is insoluble in common solvents such as DMF, THF, NMP, chloroform, ethyl acetate, acetone, methanol, isopropanol and water (S26). The cured polymer was smooth, with AFM analysis revealing an average surface roughness of $0.37 \pm 0.07 \mathrm{~nm}$ and a root mean square roughness of $0.92 \pm 0.36$ (Fig $2 \mathrm{~d}$ and S27).
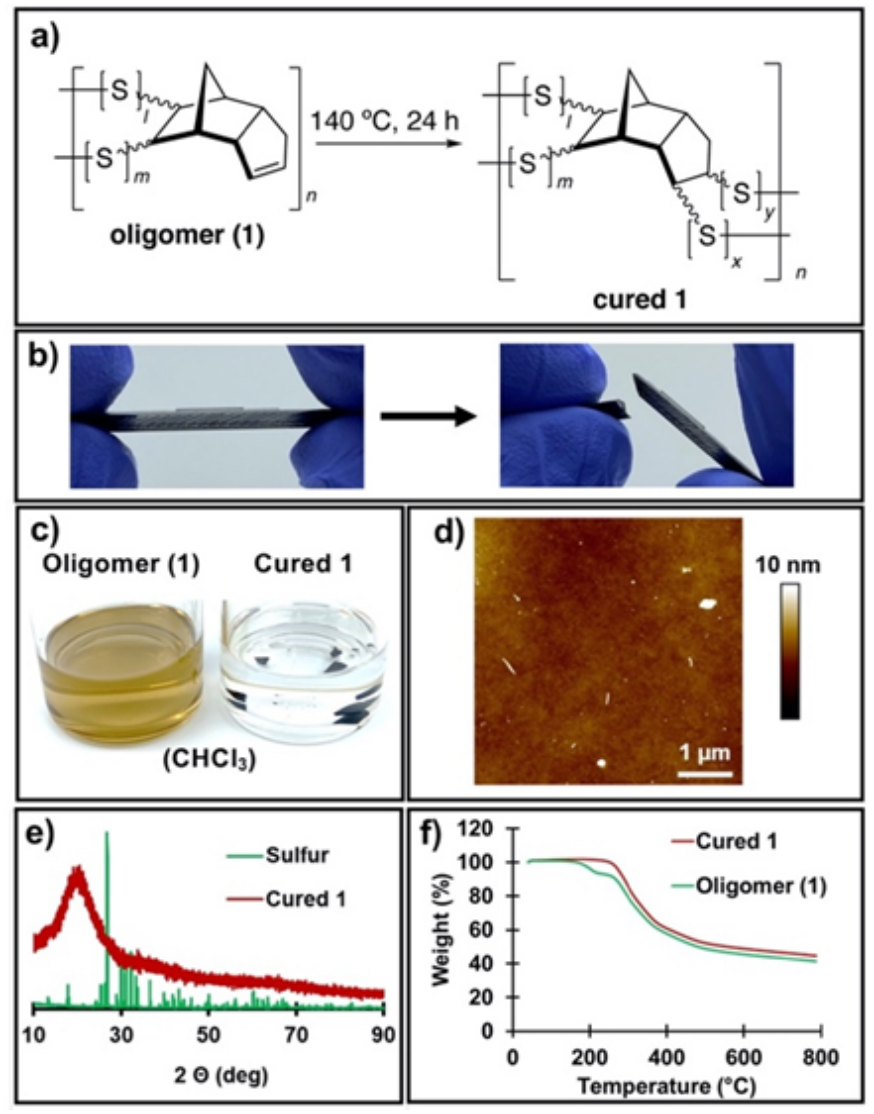

Figure 2. a) Process for curing oligomer 1, and an approximate structure of the proposed product. b) Image of cured product and its rigid and inflexible nature. c) Oligomer $\mathbf{1}(10 \mathrm{mg})$ and cured $\mathbf{1}(10 \mathrm{mg})$ in $5 \mathrm{~mL}$ of chloroform after 24 hours. d) AFM analysis of cured 1 reveals a smooth surface with an average surface roughness of $0.37 \pm 0.07 \mathrm{~nm}$. e) XRD of cured 1 indicated no crystalline sulfur present. f) STA analysis of cured $\mathbf{1}$ indicates a single mass loss with an onset at higher temperatures than oligomer 1.

Atomic force microscopy nano-indentation measurements were used to determine the material properties of the cured material. Indentation curves were calibrated and analysed using procedures outlined by Sader et $\mathrm{a}^{22}$ and Kontomaris et $\mathrm{al}^{23}$ (S28-S29). This analysis yielded values of $1.49 \pm 0.36 \mathrm{GPa}$ for the elastic modulus and $0.25 \pm 0.09 \mathrm{GPa}$ and $25.9 \pm 9.6$ for the surface area hardness and
Vickers hardness, respectively. The elastic modulus is comparable to values reported for nylon, PVC and polycarbonate ${ }^{24}$ and the hardness is similar to values reported for nylon, PMMA and polystyrene. ${ }^{24,25}$

The TGA profile of cured 1 was distinct from the oligomer precursor, with the former having only a single mass loss starting at $250{ }^{\circ} \mathrm{C}$. Such a profile may be attributable to the lower sulfur rank and stronger S-S bonds formed after curing. ${ }^{20,21,26}$ After reducing cured 1 with either $\mathrm{LiAlH}_{4}$ or $\mathrm{NaBH}_{4}$ in THF, GC-MS analysis revealed a complex mixture of products, but ones consistent with both S-S metathesis and addition of the polysulfide to the unreacted alkene (see S30-S51 and for additional discussion). Overall, these results indicated that oligomer $\mathbf{1}$ can be cured to provide a material that is more chemically and thermally resilient.

Expanding on the analytical reduction of cured 1 with hydrides, we next explored if reduction could be used in chemical recycling of the cured polymer system. The aim was to reduce cured $\mathbf{1}$ to a small molecule monomer or mixture of monomers, and then re-cure that system to re-access cured 1 or a similar material. Accordingly, $4.4 \mathrm{~g}$ of cured 1 was first reduced with $\mathrm{NaBH}_{4}$, quenched and extracted with THF. GC-MS analysis of the product mixture was consistent with the previous reduction of cured $\mathbf{1}$ and includes mixtures of thiols and small-molecule cyclic polysulfides (S52-S56). When this mixture dried and cured again for 24 hours at $140{ }^{\circ} \mathrm{C}$, the re-cured material had the same hard and brittle characteristics as cured 1 . It was thought that the reaction of the thiols with each other by oxidation and/or reaction of the thiols with the cyclic polysulfides could provide a polysulfide polymer similar to the original cured 1 . However, TGA analysis of both materials (cured $\mathbf{1}$ and the reduced and re-cured cured 1) revealed differences. The mass loss onset of the re-cured material occurs at a lower temperature $\left(225^{\circ} \mathrm{C}\right)$ and $13 \%$ more total mass is lost when compared to cured $\mathbf{1}$ (S57) Additionally, elemental analysis showed a higher carbon and a lower sulfur content in the recured material-likely the result of the formation of sodium sulfide during the reduction, which would be lost on workup (S58). The solubility of the re-cured material was investigated using the same solvents as for cured $\mathbf{1}$. The re-cured material was fully soluble in THF, chloroform and NMP; partially soluble in DMF and slightly soluble in acetone (S59). These results indicate that while the recured material is similar in physical appearance to cured $\mathbf{1}$, the product of chemical recycling is not as solvent resistant possibly due to loss of sulfur in the reduction step. Thus, while this first-generation recycling strategy is imperfect, it does illustrate the ability to break down these polysulfides by reduction, with the potential to then repolymerise the product to access new materials. Additionally, these experiments show that the otherwise chemically resilient cured-1 could be degraded with reducing agents - a capability that could find use in removing coatings made from cured-1, as discussed below.

Next, the sulfur-DCPD polymer was investigated in coatings applications. Accordingly, oligomer 1 was made using the optimised method (equal masses of sulfur and DCPD reacted directly at $140{ }^{\circ} \mathrm{C}$ under nitrogen for 2 hours). The product was then dissolved in a solution of chloroform (1.66 g oligomer 1 in $150 \mathrm{~mL}$ of chloroform) and stirred with $16.6 \mathrm{~g}$ of silica gel (46-63 $\mu \mathrm{m}$ particles, $60 \AA$ pore size). The solvent was removed by rotary evaporation, providing the modified silica as a free-flowing powder, evenly coated with oligomer 1 (Fig. 3). The coated silica was then transferred to a vial and cured in an oven at $140{ }^{\circ} \mathrm{C}$ for 24 hours. After this time, the polymer darkened in colour and was no longer soluble in chloroform. EDX analysis of the surface of the cured, coated silica indicated the presence of sulfur from the polymer, even after extensive washing with chloroform (Fig 3). In contrast, if the polymer was not cured, this 
chloroform wash removed the polymer. This result indicated that curing renders the polymer coating resistant to solvent.

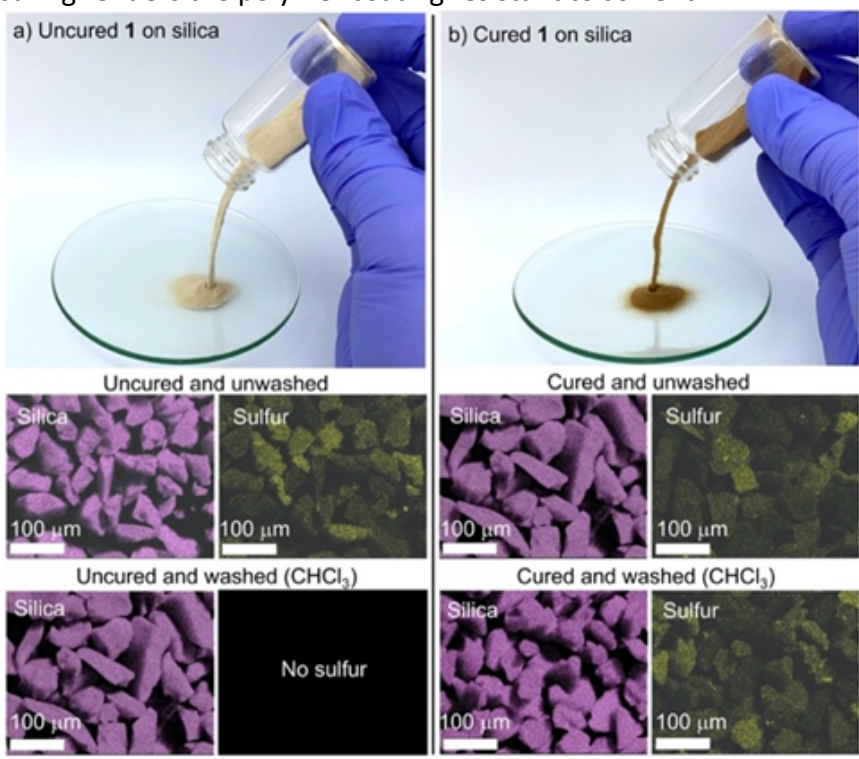

Figure 3. a) Silica gel coated with oligomer 1 before curing (10 wt\% coating). Washing this material with chloroform $(6 \times 10 \mathrm{~mL})$ removes the sulfur oligomer 1, as indicated by EDX analysis. b) Silica gel coated with cured 1 (10 wt\% coating). b) The polymer darkens in colour upon curing. Washing this material with chloroform $(6 \times 10 \mathrm{~mL})$ does not remove the polymer coating, as indicated by the sulfur signal in the EDX analysis. Both materials were effective in removing $\mathrm{HgCl}_{2}$ from water

Next, the silica-coated with cured 1-was evaluated as a mercury sorbent. Mercury remediation, particularly from water, has become increasingly important to meet obligations under the Minamata Convention-the treaty that governs the use and control of this toxic metal. ${ }^{27}$ And while a number of sorbents for mercury are known, ${ }^{28-31}$ there still remains a need for low-cost sorbents. For this reason, polysulfides made by inverse vulcanisation have emerged as versatile materials for mercury remediation, 6, 10, 32-34 but there are few reports of mercury sorbents that are generally solvent resistant. In the oil and gas sector, for instance, there are scenarios in which mercury sorbents would have to be effective in capturing mercury from mixtures of water and hydrocarbons. ${ }^{35}$ We viewed the cured sulfur DCPD copolymer as a potentially useful sorbent in this context given its solvent resistance.

First, mercury removal from water was tested. Accordingly, 100 $\mathrm{mg}$ of the coated silica (either cured or uncured) were added to a 45 $\mathrm{mL}$ solution of $\mathrm{HgCl}_{2}$ in water ( $5 \mathrm{ppm}$ mercury) and agitated using an end-over-end mixer. Uncoated silica was tested as a negative control. Silica coated with cured $\mathbf{1}$ followed by extensive chloroform washing was also tested (S60). All tests were carried out in triplicate and the mercury concentration in the water was measured by cold vapour atomic absorption spectroscopy (CVAAS) every 30 minutes. The results (S61-S62) indicate that the polymer coated silica was highly effective in mercury sorption. The uncured sample removed $>99 \%$ of mercury within 2 hours. Both cured samples removed at least $92 \%$ of mercury over the same time period (S62). These results indicate that curing slightly reduces the effectiveness as a mercury sorbent, but curing also renders the sorbent solvent resistant. The unmodified silica gel only removed $14 \%$ of the mercury, meaning the coating plays a key role in mercury uptake. To detemine the maximum mercury capacity of the material, an isotherm analysis was carrier out and the data fitted using the Langmuir model (S63). The capacity of the sorbent (polymer and silica) was found to be $5 \mathrm{mg} / \mathrm{g}$.
However since $90 \%$ of the sorbent is silica gel and only $10 \%$ polymer by mass, this corresponds to a capacity of $50 \mathrm{mg}$ mercury per gram of polymer coating. And while this sorption capacity is lower than many high performance sorbents such as activated carbon and other sophisticated porous or nanostructured materials, ${ }^{31,36}$ the sorption capacity is comparable to other sulfur polymer sorbents. ${ }^{32}$

Next, a mixture containing equal volumes of water and diesel fuel was prepared and spiked with $\mathrm{HgCl}_{2}$ so that the mercury concentration was $5 \mathrm{ppm}$. To $45 \mathrm{~mL}$ of this mixture, a $100 \mathrm{mg}$ portion of the silica, coated with 1 and cured, was added. The mixture was agitated to create an emulsion (S64), and then rotated on an endover-end mixer for 2 hours. The mercury concentration of the water layer was monitored when the sorption experiment was started, and then every $\mathbf{3 0}$ minutes thereafter. The water and diesel layers were separated using a centrifuge and the mercury content in the water was measured by CVAAS. Over 2 hours, $92 \%$ of the mercury was removed (S65). The diesel did not interfere in the mercury capture or dissolve the polymer sorbent, indicating the cured coating is tolerant of these hydrocarbon mixtures.

A final application of oligomer $\mathbf{1}$ was to use it as a protective coating for aluminium. Previous studies have shown that sulfur polymers are resistant to acid, ${ }^{37,}, 38$ but there remains a need for a generally solvent processible sulfur prepolymer to facilitate deployment in coatings applications. We therefore evaluated if oligomer 1 could meet this need. Accordingly, small amounts of cured 1 (57-77 $\mathrm{mg}$ ) were tested for acid resistance first by submerging it in $\mathrm{HCl}, \mathrm{H}_{2} \mathrm{SO}_{4}, \mathrm{HNO}_{3}, \mathrm{TFA}, \mathrm{H}_{3} \mathrm{PO}_{4}$, or acetic acid. The polymers were removed after 24 hours, rinsed with deionised water, dried and weighed to determine if the acid had dissolved or degraded the cured polymer. Only two acids showed any effect on the polymer. Sulfuric acid dissolved $3 \%$ of cured 1 in 24 hours and nitric acid dissolved $6 \%$ in 24 hours (S66). This was a promising result and showed that the polymer is only minimally affected by a range of acids, including the highly aggressive and oxidising sulfuric and nitric acids. To test the acid resistivity on a polymer coated piece of aluminium, $1.0 \mathrm{~g}$ of oligomer 1 was dissolved in chloroform $(2 \mathrm{~mL})$. A $100 \mu \mathrm{L}$ aliquot of this solution was then added to the surface of aluminium wafer $\left(1 \mathrm{~cm}^{2}\right)$. After the solvent evaporated, the coated metal was cured at $140{ }^{\circ} \mathrm{C}$ in an over for 24 hours. The final coating was $30 \mathrm{mg}$ in mass. The cured polymer has a smooth, black finish and adhered to the metal (Fig 4a).

\section{a) Aluminium coated with 1 and cured}
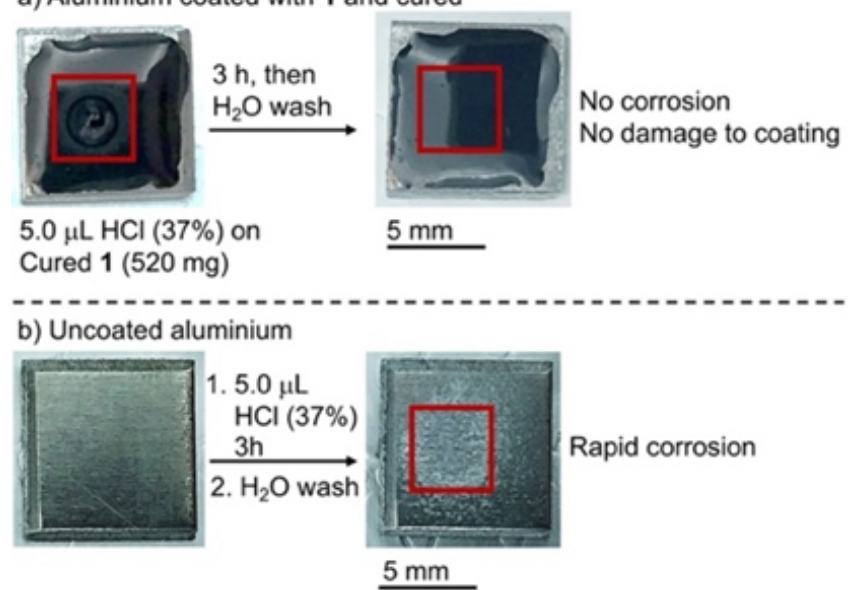

Figure 4. a) A solution of $1(100 \mu \mathrm{L}, 500 \mathrm{mg} / \mathrm{mL}$ in chloroform) was added to an aluminium wafer and cured at $140{ }^{\circ} \mathrm{C}$ for $24 \mathrm{~h}$. The cured coating adhered 
to the metal and was resistant to concentrated $\mathrm{HCl}$. b) The uncoated aluminium reacted rapidly with concentrated $\mathrm{HCl}$.

To test for acid resistance, $\mathrm{HCl}(37 \%, 5 \mu \mathrm{L})$ was added to the surface of the polymer. After 3 hours, the acid was washed away with water No reaction or corrosion was apparent by inspection (Fig. 4 and S67). In contrast, the uncoated aluminium corrodes rapidly upon exposure to the same $\mathrm{HCl}$ solution (Fig. 4 and S68). The cured DCPD sulfur copolymer was clearly resistant to acid, providing a protective coating for the aluminium wafer.

\section{Conclusions}

In conclusion, a safe and robust protocol was developed to obtain sulfur-DCPD copolymers. The method features the formation bench-stable pre-polymer that can be cured to provide a solvent- and acid-resistant coating. The sulfur content and chemical resistance was instrumental in the removal of mercury from mixtures of water and diesel fuel.

\section{Conflicts of interest}

There are no conflicts of interest to declare

\section{Acknowledgements}

The authors thank the Australian Research Council (DP200100090, T.H. and J.M.C) and the Royal Society (University Research Fellowship, T.H.) for funding. T.H. and J.M.C. also thank the Royal Society for an International Exchange grant in support of this research (IES $\backslash R 3 \backslash 170364$ ). This research was supported by an Australian Government Research Training Program (RTP) Scholarship (M.M.). The authors also acknowledge the support of the Microscopy Australia research facility at Flinders University. This work was performed in part at the South Australian node of the Australian National Fabrication Facility under the National Collaborative Research Infrastructure Strategy to provide nano and microfabrication facilities for Australia's researchers.

\section{Notes and references}

1. B. R. Currell, A. J. Williams, A. J. Mooney and B. J. Nash, in New Uses of Sulfur, ed. J. West, American Chemical Society, Washington, DC, 1975, vol. 140, pp. 1-17.

2. T. A. Sullivan, W. C. McBee and D. D. Blue, in New Uses of Sulfur, ed. J. R. West, American Chemical Society, Washington, D. C., 1975, vol. 140, ch. Chapter 4, pp. 5574.

3. L. Blight, B. R. Currell, B. J. Nash, R. A. M. Scott and C. Stillo, in New Uses of Sulfur-II, ed. D. J. Bourne, American Chemical Society, Washington, D. C., 1978, vol. 165, pp. 13-30.

4. B. K. Bordoloi and E. M. Pearce, in New Uses of Sulfur-II, ed. D. J. Bourne, American Chemical Society, Washington, D. C., 1978, vol. 165, ch. 3, pp. 31-53.

5. L. B. Blight, B. R. Currell, B. J. Nash, T. M. Scott and C. Stillo, Br. Polym. J., 1980, 12, 5-11.
J. A. Smith, S. J. Green, S. Petcher, D. J. Parker, B. Zhang, M. J. H. Worthington, X. Wu, C. A. Kelly, T. Baker, C. T. Gibson, J. A. Campbell, D. A. Lewis, M. J. Jenkins, H. Willcock, J. M. Chalker and T. Hasell, Chem. Eur. J., 2019, 25, 10433-10440.

8. J. A. Smith, X. Wu, N. G. Berry and T. Hasell, J. Polym. Sci. A Polym. Chem., 2018, 56, 1777-1781.

9. B. Zhang, S. Petcher and T. Hasell, Chem. Commun., 2019, 55, 10681-10684.

10. J. M. Scheiger, C. Direksilp, P. Falkenstein, A. Welle, M. Koenig, S. Heissler, J. Matysik, P. A. Levkin and P. Theato, Angew. Chem. Int. Ed., 2020, 59, 18639-18645.

11. X. Wu, J. A. Smith, S. Petcher, B. Zhang, D. J. Parker, J. M. Griffin and T. Hasell, Nat. Commun., 2019, 10, 647.

12. W. J. Chung, J. J. Griebel, E. T. Kim, H. Yoon, A. G. Simmonds, H. J. Ji, P. T. Dirlam, R. S. Glass, J. J. Wie, N. A. Nguyen, B. W. Guralnick, J. Park, Á. Somogyi, P. Theato, M. E. Mackay, Y.-E. Sung, K. Char and J. Pyun, Nat. Chem., 2013, 5, 518-524.

13. J. J. Griebel, R. S. Glass, K. Char and J. Pyun, Prog. Polym. Sci., 2016, 58, 90-125

14. Y. Zhang, R. S. Glass, K. Char and J. Pyun, Polym. Chem., 2019, 10, 4078-4105.

15. M. J. Worthington, R. L. Kucera and J. M. Chalker, Green Chem., 2017, 19, 2748-2761.

16. J. M. Chalker, M. J. Worthington, N. A. Lundquist and L. J. Esdaile, Top. Curr. Chem., Springer, 2019, 377, 125-151.

17. M. E. Duarte, B. Huber, P. Theato and H. Mutlu, Polym. Chem., 2020, 11, 241-248

18. B. Meyer, Chem. Rev., 1976, 76, 367-388.

19. K. Orme, A. H. Fistrovich and C. L. Jenkins, Macromolecules, 2020, 53, 9353-9361.

20. N. A. Lundquist, A. D. Tikoalu, M. J. H. Worthington, R. Shapter, S. J. Tonkin, F. Stojcevski, M. Mann, C. T. Gibson, J. R. Gascooke, A. Karton, L. C. Henderson, L. J. Esdaile and J. M. Chalker, Chem. Eur. J., 2020, 26, 10035-10044.

21. S. J. Tonkin, C. T. Gibson, J. A. Campbell, D. A. Lewis, A. Karton, T. Hasell and J. M. Chalker, Chem. Sci., 2020, 11, 5537-5546.

22. J. E. Sader, R. Borgani, C. T. Gibson, D. B. Haviland, M. J. Higgins, J. I. Kilpatrick, J. Lu, P. Mulvaney, C. J. Shearer, A. D. Slattery, P.-A. Thorén, J. Tran, H. Zhang, H. Zhang and T. Zheng, Rev. Sci. Instrum., 2016, 87, 093711.

23. S. V. Kontomaris and A. Malamou, Mater. Res. Express, 2020, 7, 033001.

24. A.-Y. Jee and M. Lee, Polym. Test., 2010, 29, 95-99.

25. F. J. Baltá Calleja, Adv. Polym. Sci., 1985, 66, 117-148.

26. M. J. H. Worthington, R. L. Kucera, I. S. Abuquerque, C. T. Gibson, A. Sibley, A. D. Slattery, J. A. Campbell, S. F. K. Alboaiji, K. A. Muller, J. Young, N. Adamson, J. R. Gascooke, D. Jampaiah, Y. M. Sabri, S. K. Bhargava, S. J. Ippolito, D. A. Lewis, J. S. Quinton, A. V. Ellis, A. Johs, G. J. L. Bernardes and J. M. Chalker, Chem. Eur. J., 2017, 23, 16219-16230.

27. United Nations Environment Programme, ,Minamata Convention on Mercury, https://www.mercuryconvention.org/sites/default/files/d ocuments/information document/Minamata- 
Convention-booklet-Sep2019-EN.pdf, (accessed 12th of October, 2021).

28. G. de Vargas Brião, J. Resende de Andrade, M. G. Carlos da Silva and M. G. Adeodato Vieira, Environ. Chem. Lett., 2020, 18, 1145-1168.

29. F. O. Ochedi, Y. Liu and A. Hussain, J. Clean. Prod, 2020, 267, 122143.

30. D. Raj and S. K. Maiti, Environ. Monit. Assess., 2019, 191, 566.

31. L. Wang, D. Hou, Y. Cao, Y. S. Ok, F. M. G. Tack, J. Rinklebe and D. O'Connor, Environ. Int., 2020, 134, 105281.

32. J. M. Chalker, M. Mann, M. J. H. Worthington and L. J. Esdaile, Org. Mater., 2021, 3, 362-373.

33. M. P. Crockett, A. M. Evans, M. J. H. Worthington, I. S. Albuquerque, A. D. Slattery, C. T. Gibson, J. A. Campbell, D. A. Lewis, G. J. L. Bernardes and J. M. Chalker, Angew. Chem. Int. Ed., 2016, 55, 1714-1718.

34. J. Lee, S. Lee, J. Kim, Z. Hanif, S. Han, S. Hong and M.-H. Yoon, Bull. Korean Chem. Soc., 2018, 39, 84-89

35. S. M. Wilhelm, U.S. Environmental Protection Agency, Washington, DC, EPA/600/R-01/066 (NTIS PB2001109026), 2001.

36. J.-G. Yu, B.-Y. Yue, X.-W. Wu, Q. Liu, F.-P. Jiao, X.-Y. Jiang and X.-Q. Chen, Eviron. Sci. Pollut. Res., 2016, 23, 50565076.

37. T. Thiounn, A. G. Tennyson and R. C. Smith, RSC Advances, 2019, 9, 31460-31465.

38. C. V. Lopez, M. S. Karunarathna, M. K. Lauer, C. P. Maladeniya, T. Thiounn, E. D. Ackley and R. C. Smith, J. Polym. Sci., 2020, 58, 2259-2266. 